\title{
DEFINING AND EXPERIENCING DANGEROUS CLIMATE CHANGE
}

\author{
An Editorial Essay
}

\author{
SURAJE DESSAI ${ }^{1}$, W. NEIL ADGER ${ }^{1,2}$, MIKE HULME $^{1}$, JOHN TURNPENNY ${ }^{1}$, \\ JONATHAN KÖHLER ${ }^{1,3}$ and RACHEL WARREN ${ }^{1}$ \\ ${ }^{1}$ Tyndall Centre for Climate Change Research, School of Environmental Sciences, \\ University of East Anglia, Norwich NR4 7TJ, U.K. \\ E-mail: s.dessai@uea.ac.uk \\ ${ }^{2}$ Centre for Social and Economic Research on the Global Environment (CSERGE), \\ School of Environmental Sciences, University of East Anglia, Norwich NR4 7TJ, U.K. \\ ${ }^{3}$ Department of Applied Economics, University of Cambridge, Sidgwick Avenue, \\ Cambridge CB3 9DE, U.K.
}

\begin{abstract}
Understanding what constitutes dangerous climate change is of critical importance for future concerted action (Schneider, 2001, 2002). To date separate scientific and policy discourses have proceeded with competing and somewhat arbitrary definitions of danger based on a variety of assumptions and assessments generally undertaken by 'experts'. We argue that it is not possible to make progress on defining dangerous climate change, or in developing sustainable responses to this global problem, without recognising the central role played by social or individual perceptions of danger. There are therefore at least two contrasting perspectives on dangerous climate change, what we term 'external' and 'internal' definitions of risk. External definitions are usually based on scientific risk analysis, performed by experts, of system characteristics of the physical or social world. Internal definitions of danger recognise that to be real, danger has to be either experienced or perceived - it is the individual or collective experience or perception of insecurity or lack of safety that constitutes the danger. A robust policy response must appreciate both external and internal definitions of danger.
\end{abstract}

\section{External Definitions of Danger}

The Delhi Declaration on Climate Change and Sustainable Development, which emerged in October 2002 from the Eighth Conference of the Parties to the United Nations Framework Convention on Climate Change (UNFCCC), reiterated the need to avoid dangerous climate change as the UNFCCC's ultimate objective, as in Article 2: "stabilisation of greenhouse gas concentrations at a level that would prevent dangerous anthropogenic interference with the climate system". According to the Third Assessment Report of the Intergovernmental Panel on Climate Change (IPCC), however, deciding what constitutes dangerous climate change is a value judgement beyond the remit of the IPCC and perhaps of science itself (Smith et al., 2001; Watson et al., 2001). Implicitly, public policy institutions need to make this decision on behalf of global society and act on its implications. Yet the lack of analytical insight into dangerous thresholds is taken by some governments as 
Table I

Examples of external definitions of dangerous climate change

Danger measured through threshold in physical vulnerability

1. Large-scale eradication of coral reef systems (O'Neil and Oppenheimer, 2002)

2. Disintegration of the West Antarctic Ice Sheet (Vaughan and Spouge, 2002)

3. Breakdown of the thermohaline circulation (Rahmstorf, 2000)

4. Qualitative modification of crucial climate-system patterns such as ENSO and NAO (Timmermann et al., 1999)

5. Climate change exceeding the rate at which biomes can migrate (Malcom and Markham, 2000)

Danger measured through threshold in social vulnerability

6. Irrigation demand exceeding 50 per cent of annual seasonal water usage for agriculture in northern Victoria, Australia (Jones, 2000)

7. Depopulation of sovereign atoll countries (Barnett and Adger, 2003)

8. Additional millions of people at risk from water shortage, malaria, hunger and coastal flooding (Parry et al., 2001)

9. Destabilisation of international order by environmental refugees and emergence of conflicts (Homer-Dixon, 1991; Barnett, 2003)

10. World impacts exceeding a threshold percentage of GDP (Fankhauser, 1995; Nordhaus and Boyer, 2000)

a rationale for inaction. ${ }^{\star}$ Indeed, there is no universally established methodology or process for deciding what constitutes a dangerous level of climate change, and for whom. However, implicitly or explicitly, researchers have suggested thresholds of climate change, or of the impacts of climate change, which they themselves designate or imply as dangerous, undesirable or to be avoided. Some contrasting examples are shown in Table I.

The research process leading to these various definitions of danger has followed two different paradigms. The more frequently followed paradigm utilises what we term 'top-down' methods (Swart and Vellinga, 1994; Parry and Carter, 1998). This framework (upper left triangle in Figure 1) follows a step-wise approach and quantifies indicators of physical vulnerability based on scenarios of future socioeconomic change that are used as inputs to a series of hierarchical models. These types of assessments typically define danger, either globally or locally, in terms of physical measures (e.g., affected crop yield or water availability), threats to the continued function of some part of the non-human world, or in terms of people at risk or reduction in economic welfare. The scenarios used often assume no adap-

* According to U.S. President George W. Bush "no one can say with any certainty what constitutes a dangerous level of warming, and therefore what level must be avoided". 


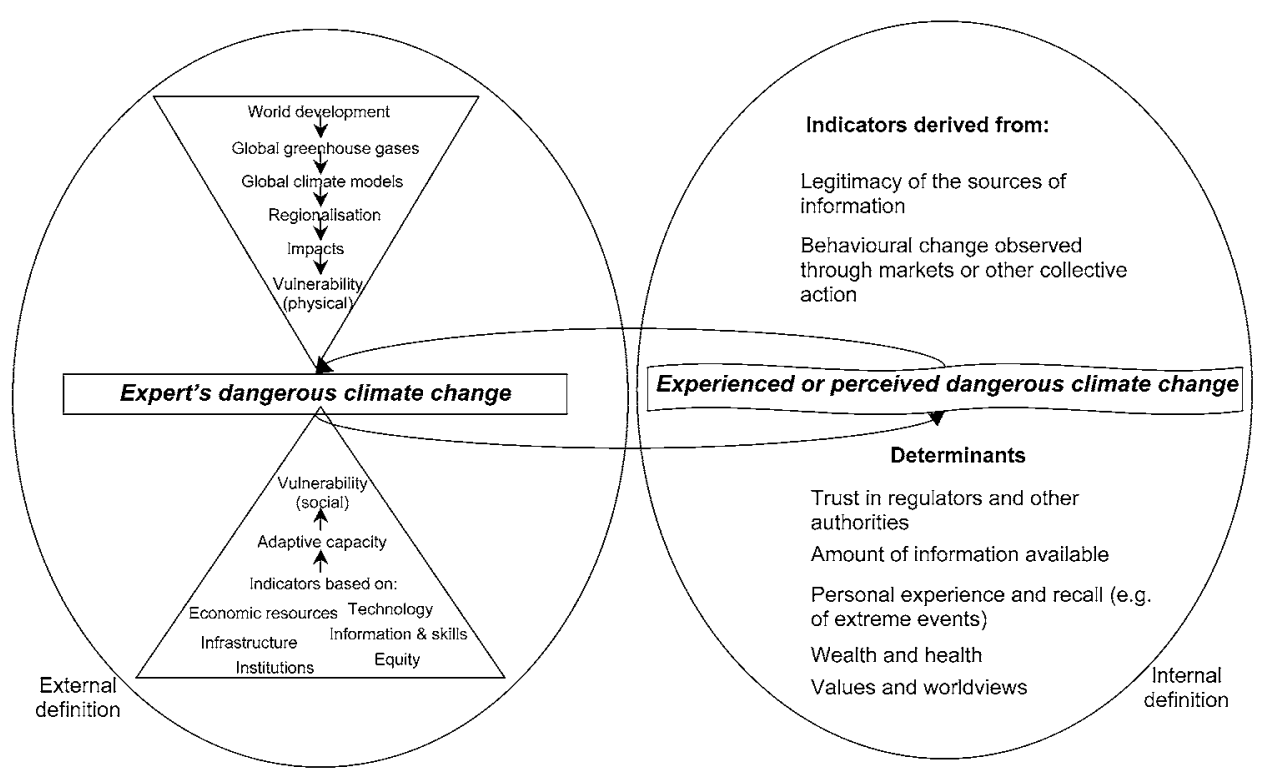

Figure 1. Components of external and internal definitions of dangerous climate change.

tation will take place as the danger threshold is approached, although sometimes a single adaptation action may be assumed and modelled. When adaptation is explicitly included, it is usually assumed that adaptation occurs on the basis of rational choices of individual actors rather than constrained by antecedent technological choices and institutional hierarchies.

The 'bottom-up' approach (as shown by the bottom left triangle in Figure 1) focuses on the social vulnerability of individuals or groups to both existing climate variability and future climate change. This approach often tests social and economic hypotheses on the determinants of vulnerability across a region or between socio-economic groups, leading to social indicators of danger and vulnerability such as poverty, lack of access to health or other services, or lack of empowerment (Bohle et al., 1994; Adger, 1999; Downing, 2003). This approach also analyses past experiences of how communities have coped with extreme events as a guide to future thresholds and adaptive behaviour (Meyer et al., 1998). In contrast to 'top-down' methods, recognising adaptive capacity is usually implicit in such approaches.

There are also a few attempts to integrate these two approaches - 'top-down' and bottom-up' - to try to derive a more holistic definition of vulnerability for the purposes of adaptation to a changing climate (e.g., see Jones et al., 2003). While recognising the scientific value and policy relevance of these research efforts, all these definitions of danger are 'external' in the sense that they are observed or modelled by 'experts' according to normative criteria relying on descriptive theories of human behaviour and decision-making. 


\section{Internal Definitions of Danger}

Danger can also be defined in terms of insecurity or lack of safety. So, for example, in the context of climate change it is the perceived insecurity arising from realised (experienced) or anticipated (perceived) impacts associated with changing extreme weather events, and often immediate threats to life and livelihood, which are of greatest concern to individuals or, collectively, to society. This definition of dangerous climate change is therefore based on psychological, social, moral, institutional and cultural processes that influence perceptions of individuals and societies about what constitutes danger and significant impact (e.g., see Berkes and Jolly, 2001; Meze-Hausken, 2003 in the context of traditional resource-dependent communities). These perceptions of danger are determined by personal experience, values, information and trust as depicted in the right side of Figure 1.

External and internal definitions of dangerous climate change interact with each other. Perceptions of what constitutes danger for an individual or institution are, to an extent, informed by a technical analysis of risk (external definition), for example, as provided by the IPCC in the form of a state-of-the-art assessment of the science of climate change. The amount of information, the legitimacy of who gives the information and the other determinants shown in Figure 1, will transform external information on thresholds and risk into different perceptions of what constitutes dangerous climate change for different coalitions, communities or individuals (internal definition). Information on the risk of an individual's house being flooded or discussion about the widespread collapse of coral reefs, for example, does much to formulate perceptions of danger.

Conversely, societal or individual perceptions of what constitutes dangerous climate change will have an impact on the formulation of research questions and ultimately on external definitions, hence the arrows between the two definitions in Figure 1. For example, public concern in the U.K. about the collapse of the thermohaline circulation (through considerable and often sensationalised media coverage; e.g., see The Scottish Evening News, 2001) contributes to the political environment within which U.K. public research funds, in both natural and social sciences, are directed into the area of rapid climate change. ${ }^{\star}$

A further dimension to the interaction between external and internal danger is the role of expectations and how external definitions of danger can change individual behaviour. In economics, expected utility theory suggests that actors anticipate future risks on the basis of available information and act accordingly depending on their time preferences. This formalises what is clear in everyday behaviour we anticipate risks and adapt to them. The prediction that an atoll country would

* See, for example, the Natural Environment Research Council six year thematic programme on rapid climate change (RAPID: http://www.soc.soton.ac.uk/rapid/rapid.php) and the Economic and Social Research Council projects dealing with the social and economic impacts of rapid climate change in the U.K. and Europe (Environment and Human Behaviour New Opportunities Programme: http://www.esrc.ac.uk/esrccontent/researchfunding/envhum.asp). 
become effectively uninhabitable through reduced land area and water availability, for example, could change behaviour such that resources would be over-exploited making the uninhabitability more likely and the prediction self-fulfilling (Barnett and Adger, 2003). Similarly, insurance markets are adjusting to the implications of external definitions of dangerous climate change in risky locations. These issues show that all definitions of dangerous climate change are socially constructed and involve reflexive processes (Stehr and von Storch, 1995; Rayner and Malone, 1998) made up of the interplay between external and internal definitions.

\section{Researching Danger}

Understanding the assumptions implicit in external definitions of dangerous climate change and their implications for perceptions of danger is important for developing a holistic understanding of climate risk management. Internal perceptions of danger have been considerably under-researched in the area of climate change. Yet the distinction between danger as an 'objective' measure and danger as experienced is well established and well recognised in other public policy areas. In the analysis of the causes and consequences of famine, for example, both external and internal definitions are recognised - external definitions are often related to food availability while internal definitions relate to perceptions of danger which trigger displacement migration or other extreme coping behaviour (de Waal, 1989; Devereaux, 1993). Similarly, in identifying poverty as the basis for social welfare policy, material aspects of poverty are easily quantified to externally define a poverty line, whereas marginalisation and social exclusion derive from how poverty is actually experienced (Townsend, 1962; Blackwood and Lynch, 1994). Comparable distinctions are also made in various areas of public health (Woodward, 2002). In these other areas of societal concern the emphasis on external or internal definitions of risk and danger leads to widely divergent public policy responses. Methods that can be applied to elicit individual or societal perceptions of risk and dangerous climate change include revealed preference and psychometric studies. The interplay between internal and external definitions can be examined using the social amplification of risk framework and participatory integrated assessment.

\subsection{OBSERVING BEHAVIOUR}

One approach for formalising internal definitions of dangerous climate change involves observing behaviour in relation to risk - in the language of economic decision-making this is known as 'revealed preference' (e.g., see Maddison, 2001). In essence, the actions of individuals within markets, in locational choices, or in political voting systems reveal patterns of acceptable risk-benefit trade-offs. Data from relevant markets or choices can therefore be used to distinguish dangerous from non-dangerous climate change. For example, some part of a decision by an 
individual to move away from their house in a flood-prone area may be because of concerns that the house could have a higher likelihood of being flooded as a result of climate change. Similarly, changes in insurance premiums relating to extreme weather events for recent decades could reveal what is being considered dangerous by this particular industry. This hedonic approach has been used to quantify the amenity value of climate for recreational tourism (Lise and Tol, 2002) and for settlement location (Maddison, 2001). The value of climate within locations is analysed by comparing house prices or wages and controlling the non-climatic factors to determine the amenity value of climate. These valuations have usually been undertaken for average climate conditions. To examine dangerous climate change, however, it would be necessary to analyse extreme weather events (e.g., days below freezing, days with gales, days with more than $25 \mathrm{~mm}$ of rain) to provide new insights on what is deemed to be unacceptable risk within a given cultural context.

Clearly, there are a number of caveats associated with this approach. The quantification of danger thresholds is relevant only if it is assumed that there is primarily a market relationship between the risk generator and the victim. In the case of climate change, this generally does not hold. Risks associated with the impacts of climate change are outside the remit of direct regulation by any single government, and are involuntary. They are therefore similar in character of future impacts to those risks associated with biotechnology or nuclear waste disposal. As yet, there is no relationship between the victim and the risk generator (greenhouse gas emitter) through standard markets (see Segerson, 1992). In the context of climate change we would argue that observed market behaviour is of limited value in defining danger and that risk characterisation and analysis requires resort to psychological methods.

\subsection{ASKING THE RIGHT QUESTIONS}

The psychometric approach examines subjective risk judgements to understand the cognitive structure and the sociopsychological factors that shape the perceived magnitude and acceptance of risks (Slovic, 1987). In general, psychometric studies ask subjects to rate risks based on various risk characteristics that shape risk perceptions and, as argued by Fischhoff et al. (1978), overcome some of the limitations of revealed preferences in situations where the link between market behaviour and risks are indirect or non-existent.

Some psychometric studies have examined dimensions of climate change. Kempton (1991) conducted ethnographic interviews to understand how individuals perceived climate change in the U.S. Similarly, Löfstedt (1991) examined perceptions of climate change and energy-use decisions in Sweden. Several other studies have examined public perception of climate change in the context of other similar risks in the public consciousness (e.g., see Bostrom et al., 1994; Read et al., 1994; Dunlap, 1998; O'Connor et al., 1999; Kasemir et al., 2000; Poortinga 
and Pidgeon, 2003). To our knowledge, none of these studies have made an explicit link between public perception of climate change and issues relating to dangerous climate change. McDaniels et al. (1996) and Board et al. (1998) are the closest to making this connection by measuring perceived risk associated with climate change impacts. Board et al. (1998) focused on the likelihood of climate change having an impact on individual and planetary well-being (e.g., personal health or food shortages). The survey data, based on U.S. respondents, showed that climate change is lowest in perceived personal threat when compared to other threats (e.g., car accidents and cancer) and environmental risks (e.g., air and water pollution). This study also found that the negative impacts of climate change on others are judged to be more likely than negative outcomes on the respondent. McDaniels et al. (1996) found similar results.

In summary, psychometric analysis of the parameters of risk can contribute to insights into internal definitions of danger for climate change. Such analysis could include identification of the leverage points in turning perception into behavioural change. This can be implemented by eliciting responses to various potential climate-induced hazards according to a number of factors such as dread (danger), likelihood of hazard (uncertainty), controllability (personal), immediacy (time), and voluntariness. A combination of these characteristics of risk can provide an internal definition of dangerous climate change for groups of individuals.

To illustrate this approach, Figure 2 hypothesises where the risks identified in Table I fit in the two dimensional space of danger and uncertainty. The illustrative ranking identifies the most dangerous climate change to be the collapse of the West Antarctic Ice Sheet, but also attaches a high uncertainty to it. S/he perceives water shortages in a farm in Australia to be the least dangerous impact of climate change, a result related to the degree of familiarity or controllability perceived by individuals.

There are, however, various difficulties in operationalising the psychometric approach in the context of dangerous climate change. For example, there is little information on direct experiences of climate change, especially if we differentiate between anthropogenic climate change and natural climate variability. For marginalized and vulnerable communities the present day climate is dangerous (Bohle et al., 1994; Adger, 2003). But only part of this climate has been influenced by humans and the isolation of this contribution for particular purposes is problematic (Allen, 2003). Asking people to judge the danger of certain climate change-induced hazards might be appropriate for experts, but not for the public. Instead we need to ask people what matters and from there determine how climate change may affect what matters and thus deliver some sense of 'danger'. This is not a trivial exercise: research in this area is as resource intensive in terms of data collection as natural science experimentation or environmental monitoring. 


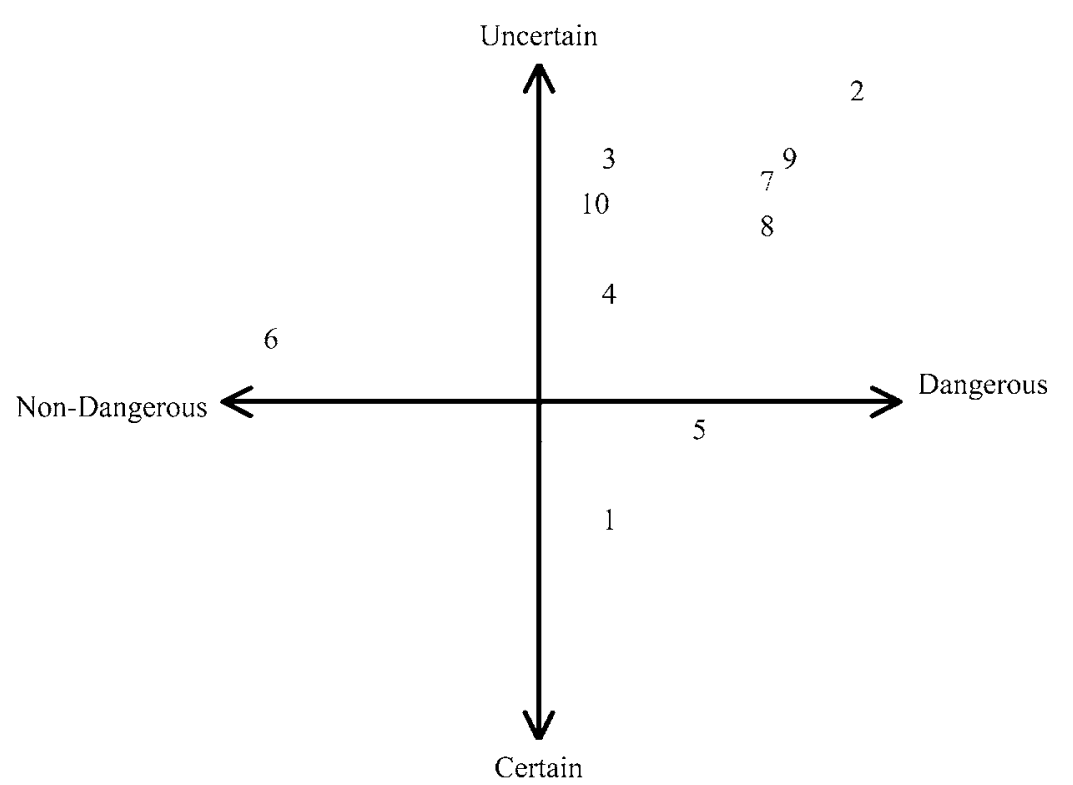

Figure 2. Conceptual diagram of climate change-induced hazards arranged by danger and uncertainty perceptions of a hypothetical individual. Numbers refer to examples in Table I.

\subsection{ANALYSING SOCIAL AMPLIFICATION/ATTENUATION}

In the case of climatic risks, scientific information about possible hazards interacts with psychological, social, institutional, and cultural processes in ways that amplify or attenuate public perception of these risks (Kasperson et al., 1988). These risk signals are subject to predictable transformations as they are filtered through various social and individual 'amplification or attenuation stations', which includes scientists, the news media, politicians, peoples' peers and others. Social amplification can also account for the observation that some events will lead to spreading 'ripples' of secondary impacts, which may instigate demands for additional institutional responses and protective actions, or impede risk management actions. Theories of social amplification and attenuation give insight into the interactions between science and society - between the external science and the feedbacks to internally defined danger (the arrows in Figure 1).

Two examples illustrate social amplification of risk between internally and externally defined danger thresholds. In 1988, the American Midwest suffered from a severe heat wave with considerable impacts (that constitutes a risk event). In the same year, NASA scientist James Hansen testified before a U.S. Senate Committee that he was "99\% certain" that global warming was underway and thus heat waves would become more frequent ('information' in this model). Also in 1988, the IPCC was created to provide scientific advice to policy-makers (institutional behaviour). There is also evidence that climate change was prominently covered by the American mass media during the period 1987-90 (Mazur, 1998), height- 
ening public perception about a global problem that was relatively low-key before this period. The publication of the IPCC First Assessment Report in 1990 led the U.N. Assembly to initiate negotiations on a Climate Change Convention that was eventually adopted in 1992 (political action).

Another example concerns extensive flooding that occurred in Britain in autumn 2000 (risk event). Various scientific and technical reports (e.g., Hulme and Jenkins, 1998; McKenzie Hedger et al., 2000) of high public profile had predicted increased flooding for the U.K. as a result of climate change ('external'). When the event occurred various influential individuals and institutions associated the floods with climate change ('internal') even though such heavy precipitation could simply be due to natural climate variability. The public reaction to these events led the U.K. government to restructure their floods programme and embark on a strategic assessment of how to manage flood risk in the long-term (institutional behaviour) (OST, 2003). Some ripple effects were also evident in other arenas such as the UNFCCC where these flood events were used to back political rhetoric for a strong Kyoto regime in order to minimise the adverse impacts of climate change.

The proponents of the social amplification of risk framework argue that its strength is to 'mesh emerging findings from different avenues of risk research, to bring various insights and analytic leverage into conjunction, and to analyse connections, interrelations, and interactions within particular social and cultural contexts' (Kasperson et al., 2003). However, this framework is not without problems. While it might be conceptually attractive, it is very hard to operationalise and to trace specific events; it also does not address the causes or physical, psychological and sociological processes of the specific underlying amplification or attenuation event. According to Pidgeon et al. (2003) there is scope for the incorporation of other theoretical models to be used in conjunction with social amplification of risk framework.

\subsection{ENGAGING IN DiALOGUE}

Ultimately, in an era of postnormal science (e.g., see Funtowicz and Ravetz (1991) or Saloranta (2001) in the context of climate change), we believe in the validity and importance of both internal and external definitions of danger. In making this statement we then have to ask: How can we actually address the issues surrounding climate change using these two different types of information? As we have seen, there are significant methodological difficulties with operationalising a social amplification/attenuation of risk framework for specific climate risks. There are also difficulties combining expressed human preferences, with all the attendant cultural, emotional, institutional and intellectual frameworks, with the natural science of changes in atmospheric behaviour and their direct impacts. To date, much of the information generated on environmental risk has ignored the first of these two types of information, and focussed on a positivist approach based on natural science. This 
has led to de-contextualised information produced by 'experts' which ignores the fundamental human aspects (e.g., see critiques by Irwin, 1995; Lash et al., 1996).

One operational attempt to rectify this has been through "participatory integrated assessment' (e.g., see Rotmans and Dowlatabadi, 1998; Kasemir et al., 2000; Tansey et al., 2002). The concept is based on recognition of the vast complexity and interlinkages between different parts of issues such as dangerous climate change, and attempts to address the problem by combining insights from different parts of natural and social sciences such as environmental chemistry, economics and cultural theory. Various tools can be employed in a complementary way, each type of tool employed for a specific relevant task (e.g., Turnpenny et al., 2003). For example, computer models can link the impacts of climate change on rainfall with economic costs of the consequent changes in water supply (the 'external' part). Such tools can be complemented by a more constructivist approach which includes the perspectives of those involved in, affected by, knowledgeable about or having relevant experience of the issue in hand (the 'internal' part) (van Asselt and Rijkens-Klomp, 2002).

There are sophisticated methods for eliciting preferences within a participatory framework such as focus groups and citizens' juries (see, for example, Stewart and Shamdasani, 1990), although the issue of representativeness of the groups remains a problem. The robustness of results from participatory research is more than simply an issue of sampling (see, for example, Morgan, 1997), but is ultimately one of representation. Representing normally excluded voices, vulnerable groups, or even values attached to the non-human world, is a transformative process that can both construct institutional innovation as well as promote in-depth understanding of the issue at hand (see, for example, Brown et al., 2001). Including a social amplification/attenuation of risk framework in a participatory integrated assessment approach could provide a rich theoretical base for extending the 'internal' part of the definition of danger within an operational framework for analysing risk.

\section{Policy Implications}

It has been argued that climate change cannot readily be tackled with traditional public policy tools (Morgan et al., 1999). We argue more specifically that defining different elements of dangerous climate change can only be done within a reflexive science framework. This requirement arises from the complexity of defining dangerous climate change, an activity fraught with uncertainties and a plurality of legitimate perspectives, whether exploring internal or external definitions of danger.

In the case of external definitions, there are still large uncertainties associated with future climate projections, impacts and adaptive responses. Also, as Table I demonstrates, there is a diversity of valid views on dangerous thresholds. Similarly, internal definitions are also clouded by uncertainties, either due to a lack 
of knowledge about the determinants of perception of danger or because it is presently impossible to attribute to anthropogenic climate change a specific extreme weather event (e.g., floods) and the dangerous experience thereof. A plurality of perspectives on internal definitions of danger is also to be expected from the methods proposed. For example, for communities living in climate sensitive areas, particularly in developing countries, present climate variability could already be considered dangerous. Conversely, post-industrial sectors of the economy, with a higher capacity to cope with weather extremes, might not consider the presentday climate dangerous, but might perceive aspects of future climate change to be so. Research also requires consideration of fairness and transparency of process (Paavola and Adger, 2002). It is important to stress that the external and internal distinction is a conceptual device, not a strict dualism. An essential challenge for postnormal science will be how to relate the two. This will require an open dialogue between those affected, those researching and those forming public policy.

Externally defined concepts of dangerous climate change, whether implicitly or explicitly formed, are being widely used. We argue that internal definitions of dangerous climate change - 'danger as experienced' - warrants at least as much attention as external definitions - 'danger as defined'. Because less attention has been given to internal definitions, we suggest that psychometric approaches, the social amplification/attenuation of risk framework and further insights from social psychology provide important methods for tackling this issue. Furthermore, the reflexivity between external and internal definitions in particular suggests that radical new methods of participatory research are necessary to truly elicit what level of climate change might be regarded as dangerous by different cultures, communities and constituencies. Much more needs to be done to recognise the importance of the social, cultural, institutional and contextural in the definition of danger. Defining long-term targets for the Climate Change Convention will require an appreciation of these different perspectives of danger. While the Convention has come a long way without a clear definition of dangerous climate change, the challenge now is to elicit and mediate values to arrive at an operational, if still dynamic, notion of 'danger'. We also expect these approaches to contribute to a more holistic, just and democratic management of climate risk.

\section{Acknowledgements}

The Tyndall Centre for Climate Change Research is core funded by three U.K. research councils - NERC, EPSRC, ESRC - and receives additional support from the U.K. Department of Trade and Industry. CSERGE is core funded by the U.K. ESRC. Suraje Dessai is currently supported by a grant (SFRH/BD/4901/2001) from Fundação para a Ciência e a Tecnologia, Portugal. Neil Adger thanks the Leverhulme Trust for support. We thank Jon Barnett, Irene Lorenzoni, Steve Schneider and Alex Haxeltine for helpful comments. 


\section{References}

Adger, W. N.: 1999, 'Social Vulnerability to Climate Change and Extremes in Coastal Vietnam', World Development 27, 249-269.

Adger, W. N.: 2003, 'Social Capital, Collective Action and Adaptation to Climate Change', Economic Geography 79, 387-404.

Allen, M.: 2003, 'Liability for Climate Change: Will it Ever be Possible to Sue Anyone for Damaging the Climate?', Nature 421, 891-892.

Barnett, J.: 2003, 'Security and Climate Change', Global Environ. Change 13, 7-17.

Barnett, J. and Adger, W. N.: 2003, 'Climate Dangers and Atoll Countries', Clim. Change 61, 321-337.

Berkes, F. and Jolly, D.: 2001, 'Adapting to Climate Change: Social-Ecological Resilience in a Canadian Western Arctic Community', Conservation Ecology 5, 18 (online) www.consecol.org/Journal/vol5/iss2/.

Blackwood, D. L. and Lynch, R. G.: 1994, 'The Measurement of Inequality and Poverty: A Policy Maker's Guide to the Literature', World Development 22, 567-578.

Board, R. J., Fisher, A., and O'Connor, R. E.: 1998, 'Public Perceptions of Global Warming: United States and International Perspectives', Clim. Res. 11, 75-84.

Bohle, H. G., Downing, T. E., and Watts, M. J.: 1994, 'Climate Change and Social Vulnerability: Toward a Sociology and Geography of Food Insecurity', Global Environ. Change 4, 37-48.

Bostrom, A., Morgan, M. G., Fischoff, B., and Read, D.: 1994, 'What do People Know about Global Climate Change? 1. Mental Models', Risk Analysis 14, 959-970.

Brown, K., Adger, W. N., Tompkins, E., Bacon, P., Shim, D., and Young, K.: 2001, 'Trade-Off Analysis for Marine Protected Area Management', Ecological Economics 37, 417-434.

Devereux, S.: 1993, Theories of Famine, Harvester Wheatsheaf, London, 208 pp.

de Waal, A.: 1989, Famine that Kills: Darfur, Sudan, 1984-1985, Clarendon, Oxford, 258 pp.

Downing, T.: 2003, 'Toward a Vulnerability/Adaptation Science: Lessons from Famine Early Warning and Food Security', in Smith, J., Klein, R. J. T., and Huq, S. (eds.), Developing Countries and Sustainable Adaptation to Climate Change, Imperial College Press, London, pp. 71-100.

Dunlap, R. E.: 1998: 'Lay Perceptions of Global Risk - Public Views of Global Warming in CrossNational Context, International Sociology 13, 473-498.

Fankhauser, S.: 1995, Valuing Climate Change: The Economics of the Greenhouse, Earthscan, London, $176 \mathrm{pp}$.

Fischhoff, B., Slovic, P., Lichtenstein, S., Read, S., and Combs, B.: 1978, 'How Safe is Safe Enough? A Psychometric Study of Attitudes toward Technological Risks and Benefits', Policy Sciences $\mathbf{9}$, 127-152.

Funtowicz, S. O. and Ravetz, J. R.: 1991: 'A New Scientific Methodology for Global Environmental Issues', in Costanza, R. (ed.), Ecological Economics: The Science and Management of Sustainability, Columbia University Press, New York, pp. 137-152.

Homer-Dixon, T.: 1991, 'On the Threshold: Environmental Changes as Causes of Acute Conflict', International Security 16, 76-116.

Hulme, M. and Jenkins, G. J.: 1998, Climate Change Scenarios for the U.K.: Scientific Report, UKCIP Technical Report No. 1, Climatic Research Unit, Norwich, 80 pp.

Irwin, A.: 1995, Citizen Science: A Study of People, Expertise and Sustainable Development, Routledge, London, 198 pp.

Jones, R. N.: 2000, 'Analysing the Risk of Climate Change Using an Irrigation Demand Model', Clim. Res. 14, 89-100.

Jones, R. N., Lim, B., and Burton, I.: 2003, 'Coping Ranges and Climate Risk Assessment: A New Approach to Vulnerability and Adaptation', Clim. Change, submitted.

Kasemir, B. Dahinden, U., Swartling, A. G., Schüle, R., Rabara, D., and Jaeger, C. C.: 2000, 'Citizen's Perspectives on Climate Change and Energy Use', Global Environ. Change 10, $169-184$. 
Kasperson, J. X., Kasperson, R. E., Pidgeon, N., and Slovic, P.: 2003, 'The Social Amplification of Risk: Assessing Fifteen Years of Research and Theory', in Pidgeon, N., Kasperson, R. E., and Slovic, P. (eds.), The Social Amplification of Risk, Cambridge University Press, Cambridge, pp. 13-46.

Kasperson, R., Renn, O., Slovic, P., Brown, H. S., Emel, J., Goble, R., Kasperson, J. X., and Ratick, S.: 1988, 'The Social Amplification of Risk: A Conceptual Framework', Risk Analysis 8, 177187.

Kempton, W.: 1991, 'Lay Perspectives on Global Climate Change', Global Environ. Change 1, 183208.

Lash, S., Szerszynski, B., and Wynne, B. (eds.): 1996, Risk, Environment and Modernity: Towards a New Ecology, Sage Publications, London, 294 pp.

Lise, W. and Tol, R. S. J.: 2002, 'Impact of Climate on Tourist Demand', Clim. Change 55, 429-449.

Löfstedt, R. E.: 1991, 'Climate Change Perceptions and Energy-Use Decisions in Northern Sweden', Global Environ. Change 1, 321-324.

Maddison, D.: 2001, The Amenity Value of the Global Climate, Earthscan, London, 144 pp.

Malcolm, J. R. and Markham, A.: 2000, Global Warming and Terrestrial Biodiversity Decline, World Wide Fund For Nature, Gland, Switzerland, 35 pp.

Mazur, A.: 1998, 'Global Environmental Change in the News - 1987-90 versus 1992-6', International Sociology 13, 457-472.

McDaniels, R., Axelrod, L. R., and Slovic, P.: 1996, 'Perceived Ecological Risks of Global Change: A Psychometric Comparison of Causes and Consequences', Global Environ. Change 6, 159-171.

McKenzie Hedger, M., Gawith, M., Brown, I., Connell, R., and Downing, T. E. (eds.): 2000, Climate Change: Assessing the Impacts - Identifying Responses. The First Three Years of the U.K. Climate Impacts Programme, UKCIP Technical Report, UKCIP and DETR, Oxford, 168 pp.

Meyer, W. B., Butzer, K. W., Downing, T. E., Turner II, B. L., Wenzel, G. W., and Wescoat, J. L.: 1998, 'Reasoning by Analogy', in Rayner, S. and Malone, E. L. (eds.), Human Choice and Climate Change, Vol. 3, The Tools for Policy Analysis, Battelle Press, Washington, D.C., pp. 217-289.

Meze-Hausken, E.: 2003, 'Migration and Climate Change: An Exploration of Human Thresholds to Climate Variability and Change - A Case-Study from North Ethiopia', Clim. Change, under revision.

Morgan, D. L.: 1997, Focus Groups as Qualitative Research, Qualitative Research Methods Series, Sage, Thousand Oaks, $80 \mathrm{pp}$.

Morgan, M. G., Kandlikar, M., Risbey, J., and Dowlatabadi, H.: 1999, 'Why Conventional Tools for Policy Analysis are often Inadequate for Problems of Global Change', Clim. Change 41, 271-281.

Nordhaus, W. D. and Boyer, J.: 2000, Warming the World: Economic Models of Global Warming, MIT Press, Cambridge, 232 pp.

O'Connor, R. E., Board, R. J., and Fisher, A.: 1999, 'Risk Perceptions, General Environmental Beliefs, and Willingness to Address Climate Change', Risk Analysis 19, 461-471.

Office of Science and Technology: 2003, 'Foresight Flood and Coastal Defence Project', Working Paper, 48 pp.

O’Neill, B. C. and Oppenheimer M.: 2002, 'Dangerous Climate Impacts and the Kyoto Protocol', Science 296, 1971-1972.

Paavola, J. and Adger, W. N.: 2002, 'Justice and Adaptation to Climate Change', Tyndall Centre Working Paper No. 23, 24 pp. Available at: http://www.tyndall.ac.uk/publications/ working_papers/wp23.pdf

Parry, M., Arnell, N., McMichael, A., Nicholls, R., Martens, P., Kovats, S., Livermore, M., Rosenweig, C., Iglesias, A., and Fischer, G.: 2001, 'Millions at Risk: Defining Critical Climate Change Threats and Targets', Global Environ. Change 11, 181-183. 
Parry, M. and Carter, T.: 1998, Climate Impact and Adaptation Assessment, Earthscan, London, 166 pp.

Pidgeon, N., Kasperson, R. E., and Slovic, P. (eds.): 2003, The Social Amplification of Risk, Cambridge University Press, Cambridge, 448 pp.

Poortinga, W. and Pidgeon, N.: 2003, Public Perceptions of Risk, Science and Governance: Main Findings of a British Survey of Five Risk Cases, Centre for Environmental Risk, University of East Anglia, Norwich, $60 \mathrm{pp}$.

Rahmstorf, S.: 2000, 'The Thermohaline Ocean Circulation: A System with Dangerous Thresholds?', Clim. Change 46, 247-256.

Rayner, S. and Malone, E. L. (eds.): 1998, Human Choice and Climate Change, Vol. 1, The Societal Framework, Battelle Press, Washington, D.C., 489 pp.

Read, D., Bostrom, A., Morgan, M. G., Fischoff, B., and Smuts, T.: 1994, 'What Do People Know about Global Climate Change? 2. Survey Studies of Educated Laypeople', Risk Analysis 14, 971-982.

Rotmans, J. and Dowlatabadi, H.: 1998, 'Integrated Assessment Modelling', in Rayner, S. and Malone, E. L. (eds.), Human Choice and Climate Change, Vol. 3, The Tools for Policy Analysis, Battelle Press, Washington, D.C., pp. 291-377.

Saloranta, T. M.: 2001, 'Post-Normal Science and the Global Climate Change Issue', Clim. Change 50, 395-404.

Schneider, S.: 2001, 'What is “Dangerous” Climate Change?', Nature 411, 17-19.

Schneider, S.: 2002, 'Can we Estimate the Likelihood of Climatic Changes at 2100?', Clim. Change 52, 441-451.

Segerson, K.: 1992, 'The Policy Response to Risk and Risk Perceptions', in Bromley, D. W. and Segerson K. (eds.), The Social Response to Environmental Risk: Policy Formulation in an Age of Uncertainty, Kluwer, Dordrecht, pp. 101-130.

The Scottish Evening News: 2001, 'Britain Heading for a Big Freeze', 6 September 2001.

Slovic, P.: 1987, 'Perception of Risk', Science 236, 280-285.

Smith, J. B., Schellnhuber, H. J., Mirza, M. A. Q., Fankhauser, S., Leemans, R., Erda, L., Ogallo, L., Pittock, B., Richels, R., Rosenzweig, C., Safriel, U., Tol, R. S. J., Weyant, J., and Yohe, G.: 2001, 'Vulnerability to Climate Change and Reasons for Concern', in McCarthy, J. J., Canziani, O. F., Leary, N. A., Dokken, D. J., and White, K. S. (eds.), Climate Change 2001: Impacts, Adaptation, and Vulnerability, Cambridge University Press, Cambridge, pp. 913-967.

Stehr, N. and von Storch, H.: 1995, 'The Social Construct of Climate and Climate Change', Clim. Res. 5, 99-105.

Stewart, D. W. and Shamdasani, P. N.: 1990, Focus Groups: Theory and Practice, Applied Social Research Methods Series, Sage Publications, Newbury Park, CA, 153 pp.

Swart, R. J. and Vellinga, P.: 1994, "The "Ultimate Objective" of the Framework Convention on Climate Change Requires a New Approach in Climate Change Research', Clim. Change 26, 343-349.

Tansey, J., Carmichael, J., van Wynsberghe, R., and Robinson, J.: 2002, 'The Future is not what it Used to Be: Participatory Integrated Assessment in the Georgia Basin', Global Environ. Change 12, 97-104.

Timmermann, A., Oberhuber, J., Bacher, A., Esch, M., Latif, M., and Roeckner E.: 1999, 'Increased El Niño Frequency in a Climate Model Forced by Future Greenhouse Warming', Nature 398, 694-696.

Townsend, P.: 1962, ‘The Meaning of Poverty', British J. of Sociology 13, 210-227.

Turnpenny, J. R., Haxeltine, A., and O'Riordan, T.: 2003, 'A Scoping Study of U.K. User Needs for Managing Climate Futures. Part 1 of the Pilot-Phase Interactive Integrated Assessment Process (Aurion Project)', Tyndall Centre Working Paper No. 31, 38 pp. Available at: http://www.tyndall.ac.uk/publications/working_papers/wp31.pdf 
van Asselt, M. B. A. and Rijkens-Klomp, N.: 2002, 'A Look in the Mirror: Reflection on Participation in Integrated Assessment from a Methodological Perspective', Global Environ. Change 12, 167184.

Vaughan, D. G. and Spouge, J. R.: 2002, 'Risk Estimation of Collapse of the West Antarctic Ice Sheet', Clim. Change 52, 65-91.

Watson, R. T. and the Core Writing Team (eds.): 2001, Climate Change 2001: Synthesis Report, Cambridge University Press, Cambridge, 397 pp.

Woodward, A.: 2002, 'Epidemiology, Environmental Health and Global Change', in Martens, P. and McMichael, A. J. (eds.), Environmental Change, Climate and Health: Issues and Research Methods, Cambridge University Press, Cambridge, pp. 290-310.

(Received 12 December 2002; in revised form 4 August 2003) 